\title{
Pattern of Clinical and Toxicological Presentation of Amphetamine Derivative-Methylenedioxymeth- amphetamine Use and its Fatal Outcome in Adolescents and Young Adults in Riyadh, Saudi Arabia
}

\author{
Sahar M. Moustafa
}

Department of Forensic Medicine and Clinical Toxicology, Faculty of Medicine, Suez Canal University, Egypt

\begin{abstract}
Background: Amphetamine derivatives have a great popularity among adolescents and young adults. Among such derivatives, a significant role is played by the recreational drug 3.4methylenedioxy-methamphetamine (MDMA, Ecstasy). The correlation between the dose of ingested ecstasy and the severity-related symptoms in humans is poor; making it is difficult to predict its clinical outcome. Aim: to describe the profile of the designer drug users and summarize the clinical and toxicological information associated with its use in adolescents and young adults besides exploring its fatality over the course of two years for assessing its clinical course and outcome. Patients and Methods: an observational cross sectional study was carried out on 59 patients from the emergency department in the complex for mental health in Riyadh from November 2010 to December 2012. Patients' blood was examined for MDMA by Immunoassay. The samples of the critical cases, which ended by death, were tested for drug concentration by liquid chromatography (LC/MS). Results: The mean patients' age was 21 years old, $77 \%$ of them were males. The prominent neuropsychiatric symptoms included coma with GCS score $3(6.7 \%)$, speech impairment (16.9\%), gait disorders (16.9\%) and aggressiveness (23.7\%). The prominent cardiac manifestations included pulse $\geq 100 / \mathrm{min}$ with GCS $3(6.8 \%)$, systolic hypertension $\geq 100$ (45.8\%). Additionally, pupils were dilated in $6.8 \%$ and hyperthermia $>39^{\circ} \mathrm{C}$ in $6.8 \%$. Most of the patients make a full recovery, two patients out of the 59 patients (3.4\%) had MDMA concentration of $1.63 \mathrm{mg} / \mathrm{L}$ and died after arrival, $5.4 \%$ needed intubation and ICU admission, and $18.2 \%$ were referred to psychiatric institutions. Conclusion: The recreational use of MDMA is highly dangerous. Studying the trend of adolescent drug use and the development of database would be very useful in the multidisciplinary approach of this public health issue.
\end{abstract}

Keywords: MDMA, Ecstasy, toxicological presentation, adolescents, young adults.

\section{Introduction}

The number of drug offenders per 100,000 persons in United States was recorded as 400, while it is 250 in Australia, several dozen in European countries ${ }^{(1)}$, and WHO report in 2001 stated that there are 162 million sufferers of the drug abuse problem all over the world ${ }^{(2)}$ The illicit marketplace of substances of abuse continually offers for sale legal alternatives to the controlled drugs, these legal alternatives substances 
are both synthetic derivatives and vegetable compounds that can produce important public health consequences and policy implications ${ }^{(3)}$. Apart from amphetamine, its derivatives also enjoy great popularity among adolescents and young adults in association with their widely understood recreational activities, among such derivatives, a significant role is played by 3.4- methylenedioxymethamphetamine (MDMA, Ecstasy) $^{(4)}$ Ecstasy is a recreational drug that is associated with a slight distortion of reality, a sense of intimacy, a sense of temporary happiness and euphoria ${ }^{(5)}$. Ecstasy was reported to share the properties of both amphetamines and hallucinogens in the nature of its side effects and residual effects which were no more severe than those of the latter two classes of drug $^{(6)}$ There is a considerable evidence that MDMA causes a variety of adverse effects to many organs in the body ${ }^{(7)}$. Increasing popularity of MDMA over the last 15 years has led to concerns over possible short-and long-term adverse effects on users $^{(8)}$. Community-based surveys in UK have reported that approximately $4 \%$ of $16-59$ years old subjects have ever taken ecstasy, which constitute more than two million people $^{(9)}$ Comparable figures have been reported from the USA and the rest of Europe ${ }^{(10)}$ Between 1997 and 1999, an increase rate of $69 \%$ in self-reported ecstasy use was reported among USA college students, while the rate remained stable in Europe $^{(11)}$. Methamphetamine derivatives have attained popularity as a recreational drug, which presents a number of challenges to the forensic toxicologist ${ }^{(12)}$. Although the surge of ecstasy use in recent times especially in young adults and the potential for adverse effects resulting from its use, human deaths associated with MDMA abuse are documented as relatively rare $^{(13)}$, the results concern of correlation between the dose of ecstasy ingested and the severity-related symptoms in humans is poor making it difficult to predict its clinical outcome ${ }^{(14)}$ However ecstasy deaths are unpredictable, deaths have followed single tablet ingestion, and there has been a report of survival following ingestion of 42 tablets $^{(15)}$ In UK, the Ecstasy-related death per 10,000 of the 15-24 year-old users ranged from 0.2 to 5.3 compared to the death rate of 1.0 from road traffic accidents in the same age-group ${ }^{(16)}$ As many as $11 \%$ of high school students in the United States have taken ecstasy, the number of deaths related to ecstasy is small when compared to the frequency of its use. Therefore, intoxication with amphetamine derivatives represents an important problem of clinical and forensic toxicology. Even of distribution of the drug group has been legally forbidden, they still represent serious threats, due to their uncontrolled administration that usually cause lethal intoxica-tions ${ }^{(17)}$. The amphetamine-based designer drug, have always has been a great challenge for forensic toxicologist. In an effort to keep up with the clandestine drug laboratories, we must be alert for very fast changes in the molecular structure of basic drug, hence, we are strained to continu-ously search for the unknown ${ }^{(18)}$. The aim of the present study was to describe the profile of that designer drug users, and summarize the clinical and toxicological information associated with its use in adolescents and young adults besides exploring its fatality over the course of two years to assess the course of poisoning caused by recreational use of these psychoactive substance.

\section{Materials and Methods}

An observational cross sectional study was conducted in the emergency department(ED) in the public complex for mental health in Riyadh, Saudi Arabia from November 2010 to December 2012 after ob- 
taining the authority approval. All data presented are based on all the information recorded in patients' files. All patients between 16 and 30 years of age who were admitted with chief complaints of designer drugs MDMA (Ecstasy) use were included. The following variables were extracted from the patients' charts: sociodemographic data, behavioral data, clinical data and toxicological data. The history of MDMA use was confirmed by the patients, friends or relatives. The age, sex and hour and day of the ED visit, heart rate, blood pressure, Glasgow Coma Scale score (GCS), body temperature and laboratory tests also any history of co-ingestion of any other drugs were recorded. In comatose patients, recovery time was defined as the time from initial presentation to ED until the patients awoke as confirmed by the note in the chart or by a GCS score of 14 or 15. For the drug detection of MDMA in patients' blood by Immunoassay screens in the lab of the complex for mental health, all chemicals and solvent were of analytical grade (Merck-eurolab), Standards of amphetamine and MDMA (Promochem). An individual standard solution of $1 \mathrm{~g} / \mathrm{L}$ was prepared in methanol and stored in the dark at $-20^{\circ} \mathrm{C}$ until use. The specimens of 1 $\mathrm{ml}$ blood were collected for routine toxicological analysis. The withdrawal of the blood was at the time of admission to hospital. Blood samples of the critical cases, which ended by death, were extracted for liquid/liquid extraction and Liquid Chromatography/ Mass Spectrometry (LQ/MS) were aliquoted into a clean $40 \mathrm{ml}$ tube. Amphetamine and MDMA were added to the sample as the internal standards at the concentration of $100 \mathrm{ng} / \mathrm{ml}$, then $1 \mathrm{ml}$ of 0.1 $M$ Tris buffer $\mathrm{pH} 9.0$ was added to the sample and centrifuged. The supernatant was mixed with $10 \mathrm{ml}$ of ethyl acetate and acidified with $0.1 \mathrm{HCL}$ and evaporated at $40^{\circ} \mathrm{C}$. The residue was reconstituted with
$100 \mu \mathrm{l}$ of HPLC mobile phase and $10 \mu \mathrm{l}$ of reconstituted extract was injected into Liquid Chromatography ${ }^{(18)}$. A Finnigan MAT liquid chromatograph (San Jose CA, USA) equipped with a pump Model TSP 4000 and auto sampler Model TSP AS 3000 with a $20 \mu$ injection loop were used in the gradient mode. The chromatographic separation was performed with a LiChroCART column $(125 \times 3 \mathrm{~mm}$ I.D., $5 \mu \mathrm{m}$ particle size $)$ filled with Purospher RP 18 and a LiChroCART column $(4 \times 4 \mathrm{~mm}$ I.D, $5 \mu \mathrm{m}$ particle size) filled with LiChroSPHER 60 RP- select (Merck, Darmstadt Germany). The mobile phase was $0.1 \%$ formic acid in water and the flow rate was $0.4 \% \mathrm{ml} / \mathrm{min}$. Chromatographic separation on a Hypersil BDS phenyl column $(100 \times 2.1 \mathrm{~mm})$ (AlltechLokern). A gradient program with water and acetonitrile, containing $0.001 \mathrm{vol} \%$ formic acid ${ }^{(18)}$.

\section{Results}

Fifty-nine patients admitted to ED department were included, 26 patients in 2011 and 33 in 2012. The mean age was 21 years old and $77 \%$ of them were males. The mean age of first use of that drug is $20.11 \pm 2.2$ years old. Poisoning was intentional in purpose of use in $86.5 \%$ of cases, 19 case (32.2\%) had a self-reported history of drug abuse in their medical report and one case only (1.7\%) had history of suicidal thoughts or suspected attempts. Some patients (11.9\%) concluded that there is a concomitant drug use but not in that session. Others (16.9\%) concluded that they have psychiatric disorders. Of the 59 cases, 26 patients (44\%) of the patients concluded that they received more than two tablets at the session. The mean number of tablets ingested was 2.7 tablets (Table 1). From the most common admission symptoms, poly symptoms followed by agitation and cardiac problems respectively in $(25.3,23.7,20.3 \%)$ of patients. 
From the prominent neuropsychiatric symptoms, 4 cases (6.7\%) were in coma with GCS score 3, speech impairment appeared in $16.9 \%$, gait disorders in $16.9 \%, 3.4$ $\%$ suffering from seizure activity and $23.7 \%$ were aggressive against the staff members (Table 2).

Table 1: The Socio-demographic characteristics of the presenting patients

\begin{tabular}{|l|l|l|}
\hline Demographic characteristics & $\mathrm{N}$ & $\%$ \\
\hline Age & & \\
$15-20$ & 20 & 33.9 \\
$21-25$ & 28 & 47.5 \\
$26-30$ & 11 & 18.6 \\
\hline Gender & & \\
Male & 45 & 67.3 \\
Female & 14 & 23.7 \\
\hline Concomitant drug use & & \\
Monointoxication & 33 & 55.9 \\
Polyintoxication & 7 & 11.9 \\
Co ingestion of ethanol & 19 & 32.2 \\
\hline Previous Psychiatric history & & \\
Depression & 2 & 3.4 \\
Anxiety disorder & 5 & 8.5 \\
Schizophrenia & 1 & 1.7 \\
Borderline disorder & 2 & 3.4 \\
\hline Previous admission due to & & \\
same reason & & \\
Once & 2 & 3.4 \\
Twice & 3 & 5.1 \\
Three times & - & - \\
No & 54 & 91.5 \\
\hline Previous use of psychoactive & & \\
substances & & \\
Yes & 19 & 32.2 \\
No & 40 & 67.8 \\
\hline Previous suicide attempts & & \\
Yes & 58 & 1.7 \\
No & & \\
\hline Reason of Poisoning & 51 & 86.4 \\
Intentional & 8 & 13.6 \\
Accidental & 33 & \\
\hline The number of tablets taken & 56 \\
Two & 26 & 44 \\
More than two & & \\
\hline & & \\
\hline
\end{tabular}

According to the Glasgow Coma Scale (GCS) only 4 patients (6.8\%) were recorded to have Glasgow Coma Scale 3 and 9 cases (15.3\%) were from $4-8$. The prominent cardiac manifestationswere pulse rate $\geq 100 /$ min with GCS $3(6.8 \%)$ and systolic Hypertension $\geq 100$ (45.8\%). Pupils were dilated in $6.8 \%$ and there were hyperthermia in 4 cases (6.8\%). Most of the patients ( $96.6 \%$ ) were monitored for 24 hours. Most of the patients made a full recovery, while 2 patients out of the total of 59 patients, (3.4\%) were dead after arrival . 3 patients (5.4\%) needed intubation and intensive care unit admission and 9 cases (18.2\%) were referred to psychiatric institutions (Table 3). The present results concluded that, in the two fatal cases in the present study the serum sample of MDMA were (1.73 and 1.54 $\mathrm{mg} / \mathrm{L})$ with a concentration mean of 1.63 $\mathrm{mg} / \mathrm{L}$. The possible cause of death in the two cases was cardiotoxicity with hyperthermia that lead to disseminated intravascular coagulopathy (DIC).

\section{Discussion}

The drug-market responds rapidly to the changes in the legal status of the psychoactive drugs, and offers new legal alternatives for sale ${ }^{(19)}$. After the development of synthetic derivatives based on fentanyl in the 1980s, a new group of designer drugs, the synthetic cathinones and amphetamines, has emerged in the recent years as a new trend, particularly among young people $^{(20)}$. Currently, the question is not whether most teenagers will use drugs, but which one (s) will they try? In addition, how many will become addicted or die? To the best of our knowledge, the present study comments on the largest sample size of ecstasy-related adverse effects in the scientific literatures, the present results concluded that a total of 59 patients were included in two year survey, 26 patients in 
2011 and 33 in 2012. This increase was simply due to the greatly increased number of people using Ecstasy.

Table 2: The clinical Neuropsychiatric characteristics of the patients' condition at the time of admission and during early hospitalization

\begin{tabular}{|l|l|l|}
\hline Clinical presentation & $\mathrm{N}$ & $\%$ \\
\hline Presenting cause of admission & & \\
Coma & 4 & 6.8 \\
Confusion & 3 & 5.1 \\
Nausea or vomiting & 8 & 13.6 \\
Agitation & 14 & 23.7 \\
Dizziness & 1 & 1.7 \\
Cardiac problem & 12 & 20.3 \\
Hyperthermia & 2 & 3.4 \\
Poly symptoms and signs & 15 & 25.4 \\
\hline Condition(AVPU Scale) & & \\
A & 36 & 61 \\
V & 10 & 16.9 \\
P & 8 & 13.6 \\
U & 5 & 8.5 \\
\hline Initial GCA score & & \\
3 & 4 & 6.8 \\
4-8 & 9 & 15.3 \\
9-12 & 10 & 16.9 \\
13-15 & 36 & 61 \\
\hline Accompanying injuries & & \\
Yes & - & - \\
No & 59 & 100 \\
\hline Patient behavior & & \\
Normal & 37 & 62.7 \\
Aggressive & 14 & 23.7 \\
Uncooperative & 8 & 13.6 \\
\hline Seizure activity & & \\
Yes & 2 & 3.4 \\
No & 57 & 96.6 \\
\hline Gait disorders & & \\
Yes & 10 & 16.9 \\
No & 49 & 83.1 \\
\hline Speech disorders & 10 & 16.9 \\
Yes & 49 & 83.1 \\
No & \\
\hline A-Alet-conscious orented V=Verbal-resp \\
\hline
\end{tabular}

$\mathrm{A}=$ Alert-conscious, oriented; $\mathrm{V}=\mathrm{Verbal}$-responds to verbal instructions; $\mathrm{P}=$ Pain-responds to painful stimuli; $U=U n r e s p o n s i v e-u n c o n s c i o u s$, responds to no stimuli; GCS= Glasgow Coma Scale
The present results are in accordance with study on Ecstasy use in Australia, which revealed that it is at its highest level on record and currently is the highest per capita in the world. A 2004 report from the Australian Institute of Health and Welfare estimated that approximately 1.2 million Australians aged 14 years or over had ever tried ecstasy $^{(21)}$.

Table 3: The toxicological data of the patients' condition at the time of admission and during early hospitalization

\begin{tabular}{|l|l|l|}
\hline Toxicological data & $\mathrm{N}$ & $\%$ \\
\hline Pulse rate & & \\
Normal & 32 & 54.2 \\
$\geq 100 /$ min & 21 & 35.6 \\
$\geq 100 /$ min with GCS 3 & 4 & 6.8 \\
$\geq 100 /$ min with GCS >3 & 2 & 3.4 \\
\hline Blood Pressure & & \\
Normal & 32 & 54.2 \\
Hypertension (systole $\geq 100$ ) & 27 & 45.8 \\
\hline Temperature & & \\
Normal & 55 & 93.2 \\
$\geq 38$ & 1 & 1.7 \\
$\geq 39^{\circ} \mathrm{C}$ & 1 & 1.7 \\
$\geq 39^{\circ}$ C with GCS 3 & 1 & 1.7 \\
$\geq 39^{\circ}$ C with GCS>3 & 1 & 1.7 \\
\hline Seizure activity & & \\
Yes & 2 & 3.4 \\
No & 57 & 96.6 \\
\hline Pupil condition & & \\
Intermediate & 55 & 93.2 \\
Wide & 4 & 6.8 \\
Small & - & - \\
\hline Management & & \\
Monitoring & 57 & 96.6 \\
Intubation & 2 & 3.4 \\
\hline Disposition & & \\
Home & 43 & 72.9 \\
Psychiatric institution & 9 & 15.2 \\
Intensive care & 3 & 5.1 \\
Dead after arrival & 2 & 3.4 \\
Left against medical advice & 2 & 3.4 \\
\hline
\end{tabular}




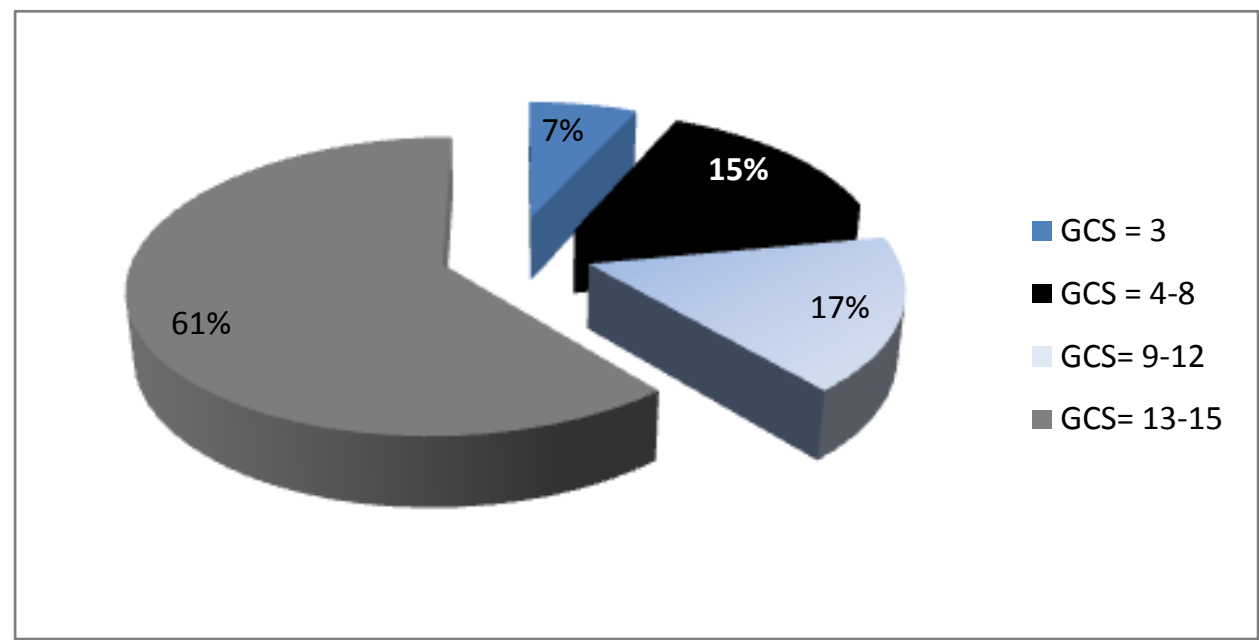

Figure 1: The initial Glasgow Coma Scale (GCS) of the presenting cases of Ecstasy users

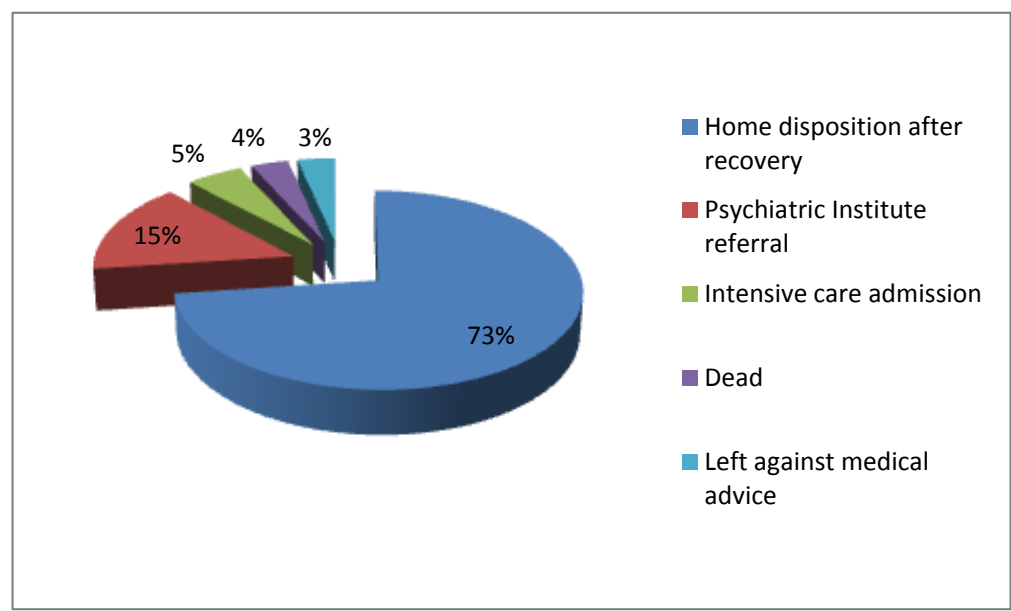

Figure 2: The clinical outcome of the presenting cases of Ecstasy users

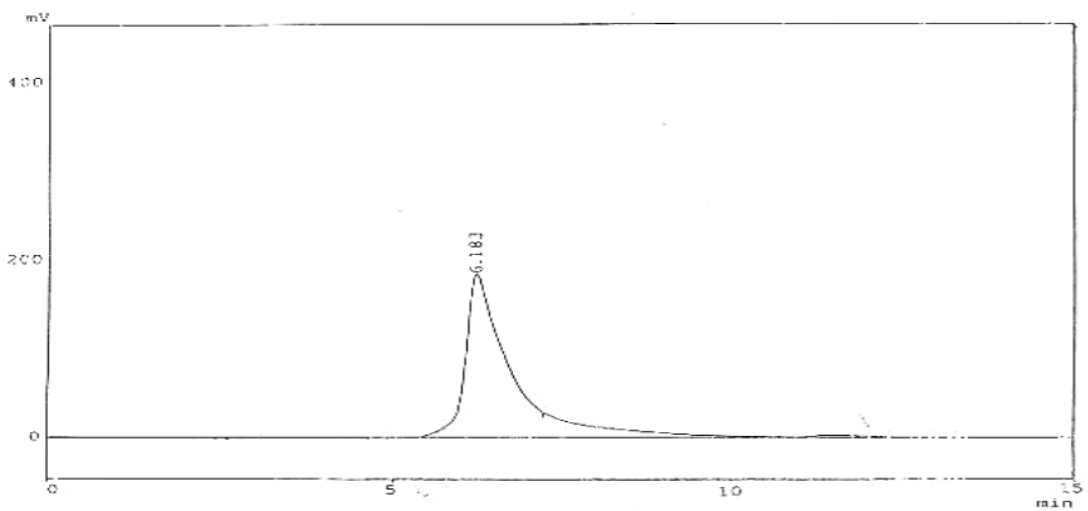

Figure 3: HPLC chromatogram showing the profile of an extracted MDMA from patient's blood 
The prevalence of illicit drug use, especially MDMA and other stimulants, has increased over the last decade among the younger section of UK population ${ }^{(22)}$, with related studies showing that approximately $50 \%$ of these ages 16-22, have tried an illicit substance, concerns has been expressed about the increasing popularity of stimulant drugs $^{(23)}$, and their association with certain youth sub cultures. Studies about drug use among young people reported a lifetime use of ecstasy between $60 \%-80 \%{ }^{(24)}$ In a study in Poland of acute poisoning in children, the results concluded that 8 children only $(1.7 \%)$ were admitted because of the Ecstasy designer drug ${ }^{(25)}$. The present results are in contrast with epidemiological studies of drug offenders which, revealed that those in their thirties rank first in Ecstasy users, accounting for around $40 \%$ of the total followed by those in their forties at about $26 \%$, those in the twenties at $16 \%$ and those under 20 years old at less than $0.3 \%$ in $\mathrm{Korea}^{(1)}$ The religious prohibition of psychoactive substances has not, however, curtailed the widespread use of drugs among people in the Arab countries. Some people believe that once alcohol is prohibited religiously, they can use other drugs with similar effects although the religious codes prohibit any substance that may impair brain functions ${ }^{(26)}$. Some studies revealed that drugs such as MDMA are commonly being abused by young people since they are easily available especially in developing countries ${ }^{(1)}$. In some young adolescents chemical are used as rite of pubertal passage and their use serves as a proof of maturation.

The present study mentioned that the most common admission symptoms were, poly symptoms presentation followed by agitation and cardiac problems respectively in (25.4, 23.7, and $20.3 \%$ ) of patients. In spite of there have been no published series describing a group of patients who have ingested ecstasy in the same environment and who subsequently developed features of MDMA toxicity ${ }^{(15)}$, the present results are in accordance with results from previous individual case reports which their clinical analysis documented an acute multi-organ failure, in particular pronounced hepatic and renal insufficiency and $\mathrm{DIC}^{(17)}$. All of these results may be due to MDMA use as Ecstasy is a synthetic amphetamine derivative which is used recreationally for its entactogenic effects. The drug works by the acute release of noradrenaline, dopamine and serotonin in the CNS and the periphery ${ }^{(27)}$. Amphetamine and its derivatives stimulate the parasympathetic system, what is manifested by numerous symptoms involving the cardiovascular system; organ failure may involve also the kidney ${ }^{(28)}$. MDMA given at single recreational dose in experimental settings has produced marked increases in blood pressure, heart rate, and mydriasis. Modest increase in the temperature was observed in some studies but not in others ${ }^{(29)}$ Subjective effects of MDMA are characterized by euphoria and wellbeing. Mild changes in body perception including visual and auditory alterations are observed but no hallucinogenic or psychotic episodes usually occur $^{(30)}$.

The present results concluded that the presenting neurological manifestations of the patients ranged from, speech impairment in $16.9 \%$, gait disorders in $16.9 \%$, dizziness and coma in $(1.7,6.7 \%)$ respectively. Designer drugs are produced with the intent to elicit effects similar to controlled substances getting round the drug laws. The neurotoxic activity of MDMA is associated with psychological effects of its prolonged usage, such as mood swings, depression and psychosis ${ }^{(31)}$. The present results are in accordance with the previous results on MDMA use in adults concluded that from the neurological manifestations 
seen in conjunction with MDMA were mood disorders, conduct disorders, attention-deficit/hyperactivity, and personality disorders ${ }^{(32)}$. In the present study, the results concluded that the mean number of tablets ingested was 2.7 tablets prior to the presenting admission time. The results were in accordance with the mean number of ecstasy tablets taken in a typical episode of consumption ranges from 1 to 2.8 tablets. More than $44 \%$ of users take more than one tablet in each session and $25 \%$ of them usually take 4 or more tablets on some occasions ${ }^{(2)}$. As with all illegally purchased controlled drugs, the contents of these tables are highly variables, consequently the WHO has concluded that the term ecstasy is generic for a wide range of compounds ${ }^{(23)}$.

Whereas serious adverse effects occurring after ecstasy use are documented only in case reports in medical literatures, the present study revealed that, the cases of fatality were 2 cases. An increasing number of reports have been published on fatal poisoning with amphetamine derivatives mostly with MDMA $^{(15)}$ The death rate among ecstasy users in UK was estimated at 0.2 to 5.3 per 10,000 users which is much lower than the death rate among heroin users (which has been reported to be as high as 81.5 per 10,000$)^{(33)}$. The results of a fatal case report due to misuse of the designer drug MDMA suggested oral intake of MDMA could result in cardiotoxicity, inducing cardiac arrhythmia and cardiovascular collapse. Because of the compromised blood supply, brain necrosis may occur, followed by severe bronchopneumonia. Ingestion of MDMA could also lead to liver damage as well as myoglobinuria resulting from rhabdomyolysis ${ }^{(34)}$. The first fatalities with recreational MDMA involved the rare overheating reaction, with core body temperature over $40^{\circ} \mathrm{C}$. Since then hyperthermic adverse reactions have continued, alt- hough hospitals now follow optimal treatment packages, so that fatalities remain very unusual $^{(35)}$. In the present study, the results concluded that the cause of death in the two cases may be due to cardiovascular collapse and may be multi-organ failure accompanied the hyperthermia and DIC in both fatal cases. The results were in accordance with the results of case study which revealed that the causes of death associated with MDMA that is frequently addressed is rapid-onset multi-organ failure, especially involving the liver. In the period between 1990 and 1999, more than 70 deaths associated with severe hepatic damage because of MDMA use were reported worldwide ${ }^{(17)}$. In another case of misuse of MDMA reported of multi-organ failure with presentation upon arrival of the hospital with cardiac problem as a leading cause of death ${ }^{(36)}$. The death in MDMA use may be due to acute severe toxic effects induced by ecstasy include hyperthermia, hyponatremia, multi-organic failure, rhabdomyolysis, DIC and serotonin syndrome, which can ultimately lead to death $^{(37)}$. In a case report of fatal poisoning in which considerable blood levels of MDMA and PMA, the results concluded that the death was due to DIC, induced by hyperthermia caused by the combined ingestion of amphetamines ${ }^{(18)}$. In a study reports all deaths related to taking Ecstasy alone or in poly-drug combination in England and Wales between 1996 and 2002 the results concluded that a total 202 fatalities occurred in the chosen period, showing a steady increase in the number of deaths each year ${ }^{(13)}$. Finally as in the previous studies which concluded that MDMA use has been associated with sudden death and cardiovascular collapse with the most common cause of death being hyperther$\mathrm{mia}^{(38)}$, these are the possible causes of death in the fatal cases of the present study. The present results concluded that, 
in the two fatal cases in the present study the serum sample concentration of MDMA were $(1.73$ and $1.54 \mathrm{mg} / \mathrm{L})$ with a mean of $1.63 \mathrm{mg} / \mathrm{L}$, which in accordance with the result in a fatal case report due to misuse of the designer drug MDMA, a serum sample obtained on admission revealed an MDMA concentration of $1.2 \mathrm{mg} / \mathrm{L}^{(34)}$. In another case of fatality due to the use of designer drug MDMA, the toxicological investigations of the autopsy specimen carried out by liquid chromatography demonstrated the presence of MDMA in the blood with concentration about $1.42 \mathrm{mg} / \mathrm{L}^{(39)}$. In a study of multiple toxicity from ecstasy on 7 cases, the MDMA plasma concentration were ranging from 0.13 to $2.4 \mathrm{mg} / \mathrm{L}$ with fatal outcome of the two cases of higher concentration of MDMA ${ }^{(15)}$.

\section{Conclusion}

The study is the first public health investigation of emergency department cases resulting from the use of MDMA, the data currently available suggests that the recreational use of MDMA must be considered highly dangerous to public health. All data indicate that MDMA will present significant interpretive challenge to forensic toxicologist as its popularity continues to grow especially in young adults. Clinical reports demonstrate acute cardiovascular and central nervous system toxicity of MDMA in combination with the high risk of death drug-related abuse. Studying the trend of adolescent drug use and the development of database would be very useful tools in the multidisciplinary approach of this public health issue. These results should raise awareness on designer consumption in adolescents and young adults and should be an alarm for public health policy. Coordination between public health departments, poison control centers, health-care providers, and law enforcement is important for timely detection that will prevent further drug-related morbidity and mortality.

\section{References}

1- Chung H, Park M, Hahn E, Choi H, Lim M. Recent trends of drug abuse and drugassociated deaths in Korea. Ann $\mathrm{N} \mathrm{Y}$ Acad. Sci. 2004; 1025: 458-464.

2- World Health Organization: Research development for accident and injury prevention. Geneva 'WHO, (2001) IPR/APR, $216 \mathrm{~m}$ 3IR. $8921 \mathrm{E}$.

3- Collins $M$. Some new psychoactive substance: precursor chemicals and synthetic-driven and products. Drug Test Anal. 2011; 3 (7- 8): 404-416.

4- Robson Ph. Forbidden drugs: Understanding drugs and why people take them 2009. http://www.booktopia.com.au/ forbidden-drugs-philip-robson

5- Szukalski B. Narcotics. Compendium of knowledge about drugs of abuse. Warazawa: Instytut Psychiatrii I Neurologii; 2005; 18: 119-23.

6- Solowij N, Hall W, Lee N. Recreational MDMA use in Sydney: A profile of ecstasy users and their experiences with the drug. Br J Addict, 2006; 87(8): 1161-1172.

7- Rietjens SJ, Hondebrink L, westerink RH, Meulenbelt J. Pharmacokinetics and pharmacodynamics of 3,4-methylenedioxymethamphetamine (MDMA) : interindividual differences due to polymorphisms and drug interactions. Crit Rev Toxicol. 2012; 42 (10): 854-876.

8- Cole JC, Sumnall HR. The pre-clinical behavioural pharmacology of 3,4methylenedioxymethamphetamine (MDMA), Neurosci Biobehav Rev 2003; 27 (3): 199-217.

9- Ramsay M, Baker P, Goulden C, Sharp C, Sondhi A. Drug misuse declared in 2000. Results from the British Crime Survey. Home Office Research Study 224. Home Office Research Development and Statistics Directorate: London, 2001; 224: 1-104.

10- Tossmann P, Boldt S, Tensil MD. The use of drugs within the techno party scene in European metropolitan cities. Eur Addict 
Res, 2001; 7 (1): 2-23.

11- Strote J, Lee JE, Wechsler H. Increasing MDMA use among college students: results of a national survey. J Adolesc. Health 2002; 30 (1): 64-72.

12- Logan BK. Amphetamines: An update on forensic issues. J Anal toxicol 2001; 25 (5): 400-404.

13- Schifano F, Oyefeso A, Corkery J, Cobain K, Jambert-Gray R, Martinotti G, Ghodse $A H$. Deaths rates from ecstasy (MDMA, MDA) and polydrug use in England and Wales (1996-2002). Hum Psychopharmacol 2003; 18 (7): 519-524.

14- Burgess C, O'Donohoe A, Gill M. Agony and ecstasy: a review of MDMA effects and toxicity, Eur. Psychiatry 2000; 15 (5): 287-294.

15- Greene SL, Dargan PI, O'Connor N, Jones $A L$, Kerins M. Multiple toxicity from 3,4methylenedioxymethamphetamine (ECSTASY). AM J Emerg Med. 2003; 21 (2):121-4.

16- Lundqvist T. Cognitive consequences of cannabis use: Comparison with abuse of stimulants and heroin with regard to attention, memory and executive functions. Pharmacol Biochem Behav 2005; 81 (2): 319-330.

17- Lukasik-Głebocka M1, Wachowiak R, Kostrzewa A, Karlikowski M, Mańkowski W, Kołowski J. Clinical and toxicological evaluation of fatal poisoning with amphetamine derivative--MDMA, ecstasy (3,4- methylenedioxymetamphetamine), Przegl Lek, 2004; 61 (4): 410-413.

18- Dams R, De Letter EA, Mortier KA, Cordonnier JA, Lambert WE, Piette $\mathrm{MH}$, Van Calenbergh S, De Leenheer AP. Fatality due to combined use of the designer drugs MDMA and PMA: A distribution study. J Anal toxicol. 2003; 27 (5): 318322.

19- Walsh C. Drugs, the internet and change. J Psychoactive drugs, 2011; 43 (1): 55-63.

20- Brandt SD, Freeman S, Sumnall HR, Measham F, Cole J. Analysis of NRG "legal highs" in the UK: Identification and formation of novel cathinones, Drug Test Anal. 2011; 3 (9): 569- 575.
21- Australian Institute of Health and Welfare (AlHW) 2004 national drug strategy household survey. First results report. AlHW 2008b.

22- Measham, F, Parker, H, Aldridge J. The teenage transition from adolescent recreational drug use to young adult dance culture in Britain in mid-1990s. J Drug Issues 1998; 28 (1): 9-32.

23- World Health Organization. Amphetamine-type stimulants. A report from the WHO meeting on amphetamines, MDMA and other psychostimulants; 1997.

24- Winstock AR, Griffiths P, Stewart D. Drugs and the dance music scene: a survey of current drug use patterns among a sample of dance music enthusiasts in the UK. Drug Alcohol Depend. 2001; 64 (1): 9-17.

25- Pawlowicz U, Wasilewska A, Olanski W, Stefanowicz M. Epidemiological study of acute poisoning in children: a 5-year retrospective study in the paediatric University Hospital in Bialystok, Poland. 2013: 30 (9): 712-716.

26- Ewaida M, Faheem A, Rakhawy Y T, Albert $\mathrm{N}$. National research on addiction, Arab Republic of Egypt, Ministry of health. Preliminary report. 1996: 12 March, PP 29-32.

27- Pilgrim JL, Gerostamoulos D, Drummer $\mathrm{OH}$, Bollmann $\mathrm{M}$. Involvement of amphetamines in sudden and unexpected death, J. Forensic Sci. 2009; 54 (2): 478485.

28- Hartung TK, Schofield E, Short AI, Parr MJ, Henry JA. Hyponatraemic states following 3,4 methyenediomethamphetamine (MDMA, 'ecstasy') ingestion. QJM. 2002; 95 (7): 431-437.

29- Liechti ME, Vollenweider FX. Which neuroreceptors mediate the subjective effects of MDMA in humans? A summary of mechanics studies. Hum Psychopharmacol 2001; 16 (8): 589-598.

30- Cami J, Farre $M$, Mas $M$, Roset $P N$, Poudevida S, Mas A, San L, de la Torre R. Human pharmacology of 3,4-methylenedioxymethamphetamine ("ecstasy"): psychomotor performance and subjec- 
tive effects. J Clin Psychopharmacol , 2000; 20 (4): 455-466.

31- Parrott AC. Recreational Ecstasy/ MDMA, the serotonin syndrome, and serotonergic neurotoxicity, Pharmacol Biochem Behav 2002; 71 (4): 837-844.

32- Greydanus DE, Patel DR. The adolescent and substance abuse: current concepts. Dis Mon. 2005: 51 (7): 392-431.

33- Vastage B. Ecstasy experts want realistic messages. JAMA.2001; 286 (7): 777.

34- Sano R, Hasuike T, Nakano M, Kominato $\mathrm{Y}$, Itoh $\mathrm{H}$. A fatal case of myocardial damage due to misuse of the designer drug MDMA. Leg Med (Tokyo) 2009; 11 (6): 294-297.

35- Halpern P, Moskovich J, Avrahami B, Bentur Y, Soffer D, Peleg K. Morbidity associated with MDMA (ecstasy) abuse: A survey of emergency department admissions. Hum. Exp. Toxicol. 2011; 30 (4): 259-266.

36- George NC, James DA, Thomas SH. Exposure to MDAl: A case report. Abstracts of the 2011 International Congress of the European Association of Poisons Centres and Clinical Toxicologists, 24-27 May 2011, Dubrovnik, Croatia. 2011; 49 ( 3): 214-215.

37- Cami J, Farre M. Drug addiction. N Engl J Med 2003; 349 (10): 975-986.

38- Gross SR, Barrett SP, Shestowsky JS, Pihl RO. Ecstasy and drug consumption patterns: A Canadian rave population study. Can J Psychiatry, 2002; 47 (6): 546-551.

39- Klys M, Rojek S, Wozniak K, RzepeckaWoźniak E. Fatality due to the use of a designer drug MDMA (Ecstasy). Leg Med (Tokyo) .2007; 9: 185-191. 